\title{
The Variation of Surface Aggregates in the Degradation Process of the Dry Red Soil in Jinsha River Dry-Hot Valley
}

\author{
Yunchuan Dai \\ School of Tourism and Geographical Science \\ Yunnan Normal University \\ Kunming, Yunnan, China \\ E-mail: daiyunchuan@gmail.com \\ Jiaxue Wang * \\ School of Tourism and Geographical Science \\ Yunnan Normal University \\ Kunming, Yunnan, China \\ e-mail:wjxynsd@163.com \\ * Corresponding Author
}

\author{
Lei Zhang \\ School of Tourism and Geographical Science \\ Yunnan Normal University \\ Kunming, Yunnan, China
}

\section{Zhi Chen}

The Faculty of Environmental Science and Engineering Kunming University of Science and Technology

Kunming, Yunnan, China

\section{Yan Xie} \\ School of Tourism and Geographical Science \\ Yunnan Normal University \\ Kunming, Yunnan, China
}

\begin{abstract}
Jinsha River Dry-hot valley is the typical region of soil degradation in southwest of China. In order to understand the mechanism and the effect of the soil degradation, sampled the dry red soil from the Jinsha River Dry-hot valley, researches and analysis were made in the surface $0 \sim 20 \mathrm{~cm}$ soil aggregates under the four different covers. The results indicated that: (1) The surface soil aggregate stability and other physicochemical properties became deteriorated, the anti-erosion ability got weak and the organic content was reduced in the degradation process of the dry red soil from vegetation to no vegetation. (2) > $0.25 \mathrm{~mm}$ water stable aggregates content (WS AC) and mean weight diameter (MWD) gradually increased, but the fractal dimension (FD) gradually reduced in the process of barren $\rightarrow$ rare-tree shrub $\rightarrow$ shrub $\rightarrow$ grass; (3) The percentage aggregate destruction (PAD0.25) demonstrated: grass < shrub < rare-tree shrub < barren; (4) The variation of the soil aggregates was not obvious between shrub, rare-tree shrub and grass. The research also indicated that: (5) The stability index of water-stable aggregates (WS AC, MWD) showed an intensely significant negative correlation with bulk density, but significant positive correlation with total porosity. Soil organic matter promotes the stability and other physical properties of water-stable aggregates, and vegetation conservation is the key to improve the structural condition of the dry red soil.
\end{abstract}

Keywords-Jinsha River; Dry-hot Valley; Dry Red Soil; Soil Degradation; Aggregates

\section{INTRODUCTION}

Soil, as the core component of the Critical Zone, is the foundation of terrestrial ecosystems ${ }^{[1]}$. Soil degradation refers to the reduction of soil quantity and the degradation of soil quality. Jinsha River Dry-hot Valley region is a typical area of soil degradation in southwest China. Getting a deep knowledge of the mechanism process and effect of dry red soil in the Jinsha River Dry-hot Valley region is an important scientific issue in this research area and also the problem to be solved concerning ecological construction, soil conservation and agricultural production.

Soil structure degradation is a major manifestation of its physical properties degradation. There has been a lot of literature studying soil degradation from the perspective of degeneration features and degradation mechanism. This paper will analyze the degradation mechanisms of the same soil type under different covers from the aspect of soil structure. Soil aggregate, as the basic unit of soil structure and function, is one of the key indicators of physical processes speed and magnitude relating to soil erosion, compaction, and soil hardening, which has affected soil porosity, water holding capacity and corrosion resistance. Especially, the stability of surface soil aggregate has a significant influence on the soil erosion and runoff and plays an important role on soil porosity maintenance, mass transport use, soil erosion, etc. The common evaluation indexes of soil aggregates include > $0.25 \mathrm{~mm}$ water stable aggregates content (WSAC), mean weight diameter $(M W D)$, percentage aggregate destruction $\left(P A D_{0.25}\right)$, fractal dimension $(F D)$, etc ${ }^{[2]}$. This paper mainly analyzes the surface $(0 \sim 20 \mathrm{~cm})$ without being affected by man-made farming under four different covers in the dry red soil area in Jinsha River Dry-hot Valley, in order to objectively reveal the changing trend of the surface soil aggregate in the process of dry red soil degradation and 
provide evidence for the understanding of the degradation mechanisms of dry red soil and the ecological rehabilitation of the degraded areas.

\section{MATERIAL AND METHOD}

\section{A. Survey on Studyarea}

The soil degradation is extremely serious in the region of Jinsha River dry hot valley, and the cultivated soil is greatly affected by human activities. The natural soil with the same slope and different covers can better reveal the variation of surface aggregates in the degradation process of the dry red soil. It is hard to find a site in the dry red soil region that simultaneously includes shrub, rare-tree shrub, grass and barren on the same slope. There are several slopes having been researched through the filed study, and the spatial analysis software of GIS, the picture processing software of RS were synthetically applied. Finally, the northwest slope in Shang Mao Ping (Located in Yong Sheng, Yunnan Province) was chosen (Tab.1).

Due to the closed terrain and foehn effect, and the unique weather is formed: The average annual precipitation is $641 \sim 650 \mathrm{~mm}$, and its $80 \sim 90 \%$ precipitation is in July to October. The annual evaporation is 3-6 times of the annual precipitation. The annual average temperature is $21^{\circ} \mathrm{C}$, and its extreme maximum temperature is $38.8^{\circ} \mathrm{C}$, extreme minimum temperature is $1.7^{\circ} \mathrm{C}$. The annual sunshine duration is 2630 2723h. The typical vegetation on the slope includes Heteropogon contortus (L.) Beauv, Dodonaeaviscose (L.)Jacq, Jatropha carcas L, and Olea europaea.

TABLE I. CHARACTERISTICS OF THE SAMPLING SITES

\begin{tabular}{|c|c|c|c|c|c|c|}
\hline Sampling site & Coordinate/ $/ /^{\prime} / "$ & Altitude/m & Depth/cm & Slope $1^{\circ}$ & Aspect ${ }^{\circ}$ & Color \\
\hline Barren & $\begin{array}{l}100^{\circ} 31^{\prime} 05.81^{\prime \prime} \mathrm{E} \\
26^{\circ} 12^{\prime} 44.42^{\prime \prime} \mathrm{N}\end{array}$ & 1340 & $0 \sim 20$ & $45^{\circ}$ & $\mathrm{NW} 44^{\circ}$ & Light brown red \\
\hline Grass & $\begin{array}{l}100^{\circ} 11^{\prime} 04.45^{\prime \prime} \mathrm{E} \\
26^{\circ} 12^{\prime} 45.58^{\prime \prime} \mathrm{N}\end{array}$ & 1300 & $0 \sim 20$ & $35^{\circ}$ & $\mathrm{NW} 16^{\circ}$ & Brown red \\
\hline Rare-tree shrub & $\begin{array}{l}100^{\circ} 31^{\prime} 02.82^{\prime \prime} \mathrm{E} \\
26^{\circ} 12^{\prime} 47.21^{\prime \prime} \mathrm{N}\end{array}$ & 1285 & $0 \sim 20$ & $29^{\circ}$ & $\mathrm{NW} 26^{\circ}$ & Red brown \\
\hline Shrub & $\begin{array}{c}100^{\circ} 32^{\prime} 02.10^{\prime \prime} \mathrm{E} \\
26^{\circ} 12^{\prime} 49.52^{\prime \prime} \mathrm{N}\end{array}$ & 1255 & $0 \sim 20$ & $21^{\circ}$ & $\mathrm{NW} 15^{\circ}$ & Dark brown red \\
\hline
\end{tabular}

In January 2015, this paper sampled the dry red soil (natural soil) at the same slope with different covers shrub, rare-tree shrub, grass and barren. The portable device of GPS was applied to locate the sampling sites. Each surface soil sample $(0 \sim 20 \mathrm{~cm})$ was taken from the three quadrats and there are five sites in each quadrat were diagonally taken, meanwhile, the soil samples from the five sites in each quadrat were mixed and sampled $(1 \sim 1.5 \mathrm{~kg})$. The physical properties, including bulk density, total porosity and water content, were tested from the samples which were taken by the cutting ring. Soil aggregates, the physical properties of soil, were tested by applying the method of dry-wet sieving ${ }^{[3]}$. The size of the sieves are respectively $>5 \mathrm{~mm}, \quad 5 \sim 2 \mathrm{~mm}, 2 \sim 1 \mathrm{~mm}$, $1 \sim 0.5 \mathrm{~mm}, \quad 0.5 \sim 0.25 \mathrm{~mm}$ and $<0.25 \mathrm{~mm}$. WSAC $(>$ $0.25 \mathrm{~mm}), M W D, P A D_{0.25}$ and $F D$ were calculated by applying the method and the models as follows.

$$
\begin{array}{r}
W S A C=\sum_{i=1}^{n}\left(W_{i}\right) \\
P A D=\frac{m_{d}-m_{w}}{m_{d}} \times 100 \% \\
M W D=\sum_{i=1}^{n}\left(\bar{X}_{i} \times W_{i}\right)
\end{array}
$$

$$
\lg \left[\frac{M\left(r<\bar{X}_{i}\right)}{M_{t}}\right]=(3-F D) \lg \left(\frac{\bar{X}_{i}}{X_{\text {max }}}\right)
$$

Other physical properties was tested by applying the method of cutting ring (volume:100 $\mathrm{cm} 3$ ) including bulk density, water content and total prosperity ${ }^{[3]}$. The soil organic matter was tested by applying the method of potassiumdichromate volumetry.

\section{RESULTS AND DISCUSSION}

\section{A. The distribution and composition characteristics} of soil aggregates

The method of dry sieve mainly tests the soil aggregate content of the mechanical stability, and the method of wet sieve tests the soil aggregate content of the water stability. It showed the different proportion for the soil aggregates of the different granulometric classes. The content $(>$ $0.25 \mathrm{~mm}$ ) showed that: $\mathrm{shrub}>$ rare-tree shrub $>$ grass $>$ barren. There's no significant difference between rare-tree shrub and grass, but the two had the significant difference with shrub and barren. The content $(0.5 \sim 0.25 \mathrm{~mm})$ was least, and not exceeding $1.55 \%$. The dominated granulometric class in shrub and rare-tree shrub was $>$ $2 \mathrm{~mm}$, and it respectively reached to $44.85 \%, 42.50 \%$ (Fig. 1). 


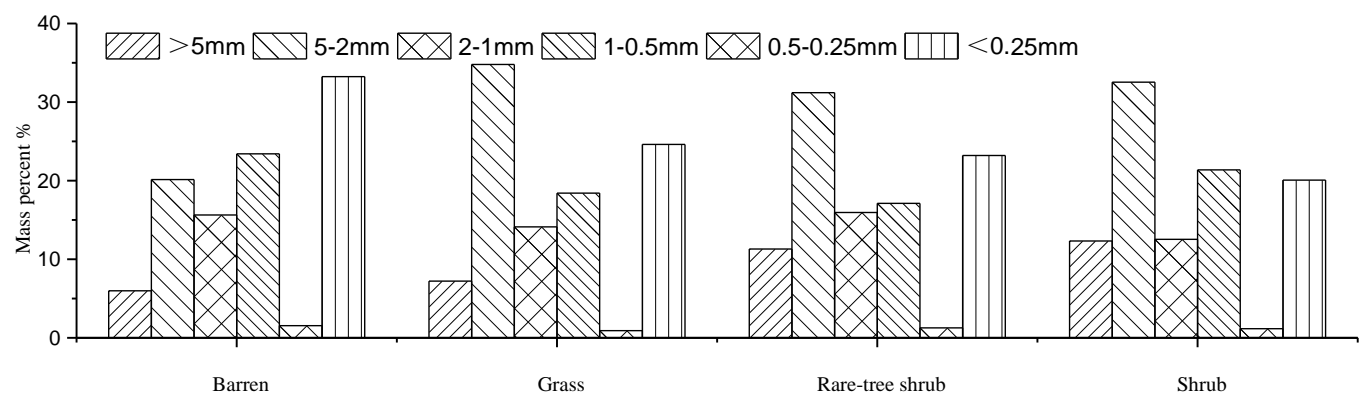

Figure 1. Composition of mechanical-stable aggregates

After having wet sieve, different soil aggregates under different covers $(>0.25 \mathrm{~mm})$ decreased obviously. Compared with dry sieve, barren, grass, rare-tree shrub and shrub reduced respectively $27.87 \%, 7.24 \%, 13.34 \%$ and $12.88 \%$. It indicated that compared with dry red soil which covered with vegetation, barren was easier to collapse when met water. Barren, grass, rare-tree shrub and shrub had minimum content among $0.5 \sim 0.25 \mathrm{~mm}$, and barren had minimum content in over $5 \mathrm{~mm}$. The results of dry and wet sieve indicated that the mechanical stability of different soil aggregates had less difference under different covers, but water stability had more. The amount of big soil aggregates was more in dry sieve than wet sieve, for dry soil aggregates contained water-stable and nonwater-stable soil aggregates. However, the large particle soil aggregates of non-water-stable were fractured, and broken down into small soil aggregates during the course of wet sieve. Therefore, the amount of water stable soil aggregates could reflect the structure and characteristics of soil aggregates better under different covers in dry red soil region (Fig. 2).

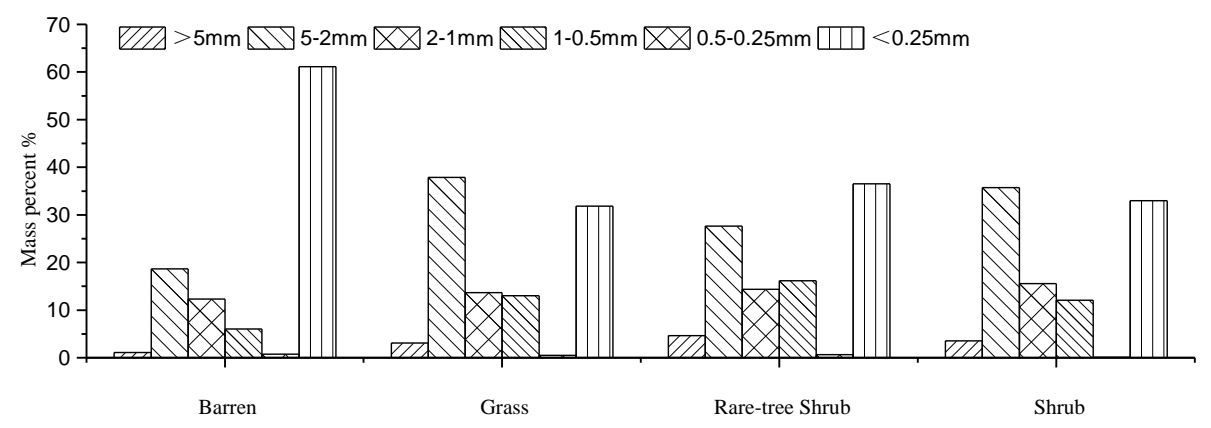

Figure 2. Composition of water-stable aggregates

\section{B. The distribution and composition characteristics of} soil aggregates

WSAC $(>0.25 \mathrm{~mm})$ is adapted to evaluate the soil aggregates stability, and it's also the critical index of anticorrosion ability ${ }^{[4]}$. The WSAC in the dry red soil region showed that: grass $(68.16 \%)>\operatorname{shrub}(67.04 \%)>$ rare-tree shrub $(63.46 \%)>$ barren $(38.9 \%)$. WSAC $(>$ $0.25 \mathrm{~mm}$ ) between grass, shrub and rare-tree shrub didn't have significant difference, but the three had the significant difference with barren, it was respectively 1.75 times, 1.72 times and 1.63 times of barren.

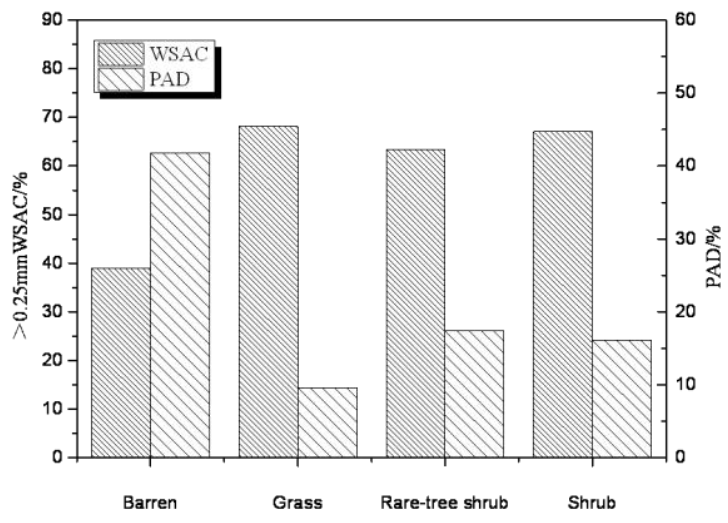

Figure 3. The variation of WSAC and PAD

$P A D_{0.25}$ value is high, which means the soil structure is easier to collapse, and soil is easier to be erode; the low value means the high soil aggregates stability ${ }^{[5]}$. The variation of $P A D_{0.25}$ in the dry red soil region showed 
that: grass $(9.60 \%)<\operatorname{shrub}(16.12 \%)<$ rare-tree shrub $(17.37 \%)<$ barren $(41.74 \%$. Compared to grass, shrub and rare-tree shrub, the PAD0.25 of barren showed the maximu $\mathrm{m}$ value, it was respectively 4.35 times, 2.59 times and 2.40 times of grass, shrub and rare-tree shrub. It means that the grass had the strongest anti-erosion ability, and barren had the weakest (Fig. 3, 4).

$M W D$ reflects the distribution situation of the soil aggregates size, the high value means the better stability ${ }^{[6]}$. $M W D$ value of WSAC under the different covers in the dry read soil region shows that: grass $(1.86 \mathrm{~mm})>$ shrub $(1.83 \mathrm{~mm})>$ rare-tree shrub $(1.63 \mathrm{~mm})>$ barren $(1.09 \mathrm{~mm})$, the same pattern as WSAC $(>0.25 \mathrm{~mm})$. $M W D$ value of grass, shrub and rare-tree shrub was respectively 1.71 times, 1.68 times and 1.50 times of barren. It means that the aggregation degree in grass was the highest in studied area, and barren was the lowest.

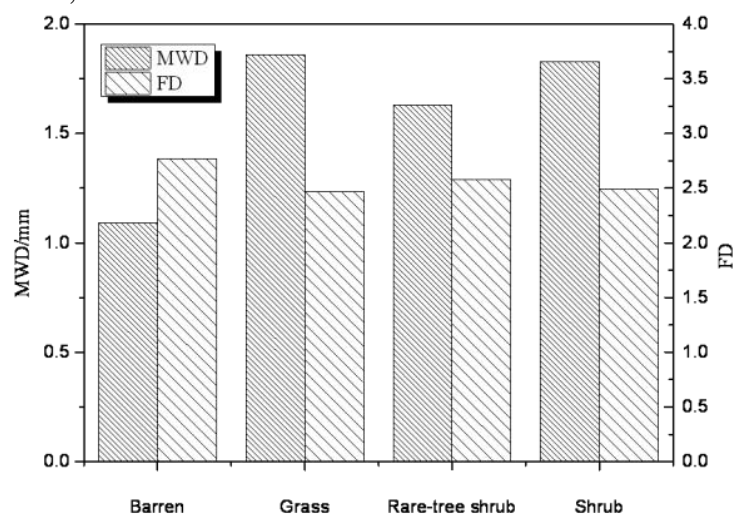

Figure 4. The variation of MWD and FD

$F D$ value of soil aggregates is one of the important indexes to evaluate the soil structure and soil erosion ${ }^{[7]}$. Lower $F D$ value means better physical and chemical properties. $F D$ value of WSAC showed that: grass $(2.47)<\operatorname{shrub}(2.49)<$ rare-tree shrub $(2.58)<$ barren (2.77). $M W D$ value presented the opposite pattern compared to WSAC. FD value of barren was significantly increasing compared with grass, shrub and rare-tree shrub. It means that the structural stability of grass was the best in studied area, barren had the worst.

\section{The influentialfactors on WSAC}

Soil bulk density, total porosity and organic matter content have a direct impact on stable water aggregate characteristics ${ }^{[8-9]}$. The size of soil bulk density reflects the soil air permeability and resistance condition of water permeability roots stretching. Thus the change of the soil bulk density has a great impact on the porosity of the soil and affects the aggregate water resistance. Bulk density was negative to WSAC and $M W D$ with the correlation index -0.693 and -0.643 respectively; the soil bulk density was positive to $P A D_{0.25}$ and $F D$ with correlation index 0.578 and 0.600 respectively which showed that the bigger the bulk density was the weaker the aggregate water resistance. Dry red soil of the soil bulk density in the studied area presented the shrub < rare-tree shrub < grass $<$ barren. The bulk density of shrub was distinctive from the barren which means the water resistance of the surface soil of barren was the weakest.

The total porosity of the soil is the basis of soil physical properties which can reflect the degree of osteoporosis and soil mo isture, air volume size, and the status of the soil structure and the important indicators of soil fertility[10]. The porosity of the soil is positive to WSAC and MWD with the correlation index 0.694 and $0.644(\mathrm{P}<0.05)$ respectively which means that the porosity affected the stability of the aggregate. The total porosity of the soil of Jinsha River dry-hot valleys soil degradation was between $58.11 \%$ and $62.26 \%$, presenting shrub > rare-tree shrub > grass > barren, which means vegetation cover can improve the soil pore properties and soil aggregate stability(Tab.2).

TABLE II. SOIL ORGANIC MATTER CONTENT AND PHYSICAL PROPERTY (0 20CM)

\begin{tabular}{ccccc}
\hline Sampling site & Bulk density $/\left(\mathrm{g} / \mathrm{cm}^{-3}\right)$ & $\mathrm{SOM} /\left(\mathrm{g} / \mathrm{kg}^{-1}\right)$ & Water content $/ \%$ & Total porosity $/ \%$ \\
\hline Barren & 1.11 & 13.08 & 6.78 & 58.11 \\
Grass & 1.08 & 16.92 & 9.90 & 59.25 \\
Rare-tree shrub & 1.02 & 20.04 & 22.06 & 61.51 \\
Shrub & 1.00 & 24.56 & 28.20 & 62.26 \\
\hline
\end{tabular}

The variation of organic content under the different covers was $13.08 \sim 24.56 \mathrm{~g} / \mathrm{kg}^{-1}$. Organic matter in the process of decomposing and synthesis of humus and organic colloid, and the clay minerals in the soil compounded gel, which could improve the soil structure. Soil organic matter content showed an intensely significant negative correlation with WSAC and $M W D$, and the correlation inde $\mathrm{x}$ was respectively $0.744 、 0.729(P$ $<0.01$ ), which means soil organic matter could promote the stability and other physical properties of water-stable aggregates. The soil organic content showed that: shrub $>$ rare-tree shrub $>$ grass $>$ barren. The soil organic matter content of shrub, rare-tree shrub and grass was respectively 1.88 times, 1.53 times and 1.29 times of barren. In this case, it showed that barren had no enough humus and it barely could produce organic matter (Tab.3). 
TABLE III. CORRELATION ANALYSIS FOR EACH PARAMETER OF WATER STABLE AGGREGATES

\begin{tabular}{|c|c|c|c|c|c|c|c|}
\hline Index & WSAC & PAD & MWD & FD & $\mathrm{BD}$ & SOM & $\mathrm{TP}$ \\
\hline WSAC & 1.000 & & & & & & \\
\hline PAD & $-0.988^{* *}$ & 1.000 & & & & & \\
\hline MWD & $0.989^{* *}$ & $-0.979^{* *}$ & 1.000 & & & & \\
\hline FD & $-0.978^{* *}$ & $0.972^{* *}$ & $-0.998^{\text {*** }}$ & 1.000 & & & \\
\hline $\mathrm{BD}$ & $-0.693^{* *}$ & $0.578^{* * *}$ & $-0.643^{* \pi}$ & $0.600^{*}$ & 1.000 & & \\
\hline SOM & $0.744^{* *}$ & $-0.630^{*}$ & $0.729^{* *}$ & $-0.701^{* * *}$ & $-0.968^{*}$ & 1.000 & \\
\hline $\mathrm{TP}$ & $0.694^{*}$ & $-0.580^{*}$ & $0.644^{*}$ & $-0.601^{*}$ & $-0.955^{* \pi}$ & $0.968^{*}$ & 1.000 \\
\hline
\end{tabular}

"P<0.05;" $P<0.01$. WSAC: $>0.25 \mathrm{~mm}$ WSAC:Water Stable Aggregates Content; PAD:Aggregates Dest ruction

Rate; MWD:Mean Weight Diameter; FD:Fractal Dimension; BD:Bulk Density; SOM:Soil Organic Matter; TP:Total Porosity.

\section{CONCLUSIONS}

During the degradation process of the dry red soil in Jinsha River dry-hot valley, from the vegetated(shrub, rare-tree shrub, grass) to the non-vegetated(barren), the $W S A C 、 M W D 、 S O M$ and $T P$ of the surface soil decrease significantly, while its $F D 、 P A D_{0.25}$ and bulk density showed a significant increase. It could be inferred that the main causes of the degeneration of dry red soil are low vegetation coverage, man-made destruction, which lead to the degeneration of some physical and chemical properties, such as the aggregate stability of soil and anti-erosion ability. Research also shows that there was a significant negative correlation between aggregate stability (WSAC, $M W D$ ) and bulk density, while a significant positive correlation with the organic matter and porosity.

In order to prevent soil degradation, maximizing the recovery of vegetation and avoiding damage to vegetation should be the key. The poor surface soil aggregate stability, weak anti-corrosion ability, high bulk density and density, low porosity and low organic matter content, high bulk density and density, low porosity and organic matter may be an important reason for the severely degraded soil's failure to germinate vegetation. Taking the area's unique geology, topography and climate into consideration, the degradation of topsoil may become worse unless we seek to artificial restoration. Therefore, to prevent the further degeneration of this area, taking engineering measures, biological measures and agricultural measures are necessary. Meanwhile, form a complete set of vegetation recovery mode, micro water afforestation technology and artificial fertilization are of great significance to the prevention of the soil degeneration in Jinsha River dryhot valley.

\section{ACKNOWLEDGMENT}

This work is supported by the science and technology plan of Yunnan Province (2012CA 024) and the national natural science foundation of China (41061021).

\section{REFERENCES}

[1] Li XY(2011) Mechanism of coupling, response and adaptation between soil, vegetation and hydrology in arid and semiarid regions (in Chinese). Sci SinT errae 41:1721-1730.

[2] Zhang BH, He YR, Miao GZ, Ding CC(2006) Water Characteristics and Its Eco-Environmental Effects on Soils under Different Subalpine Forests on East Slope of Gongga Mountain. Journal of Mountain Science 24(4): 504-509.

[3] Zhang L, Wang JX, Liu BQ, Xiao MJ, Cheng YF, XU LY(2015) The variation of surface soil aggregates in the degradation process of the mountain red earth zone karst. Journal of Mountain Science 33(1): 8-15.

[4] Lin PS, Gao QZ(2010)Study on Changes in Structural Properties of Purple Soils under Different Land Use. Research of Soil and Water Conservation 17(4):134-138.

[5] Zhang ZW, Fu WL, Zhang H, Yuan H, Zhu ZX, Wen ZL, Li Q(2009) Study on Structural Stability of Limestone Soil and Its Influencing Factors. Bulletin of Soil and Water Conservation 23(1):164-168

[6] Wang Y, Han X, Zhao LP(2010) Composition Characteristics of Black Soil Aggregates on Sloping Farmland. Bullet in of Soil and Water Conservation 30(5):88-90.

[7] Chen XH, Duan ZH, He HZ(2009) Fractal Characteristics of Soil Particle of Desert-Oasis Ecotone. Soils 41(1):97-101.

[8] Huang SY, Zha X(2002)Study on Soil Erosion Process and Evolution of Soil Physicochemisty Characteristics on Sloping Farmland. Jounal of Mountain Science 20(3):290-295.

[9] Cao GD, Chen JH, Xia J, Zhu HW, Jiang YC, Zhang X, Wang S M(2013) Analysis of soil physical properties under different vegetation types in the alluvial fan area of Manas River watershed. Acta Ecologica Sinica 33(1) :195-204.

[10] Zhang TL, Lu RK, Li ZP(1998) Nutrient degradation and restoration of red soil in hilly region of China. Resources and Environment in the Yangtza Basin 7(1):18-24. 